\title{
Assessment of prevalence of dental pulp stones in patients undergoing orthodontic treatment
}

\author{
Dr. Vivek Bikram Thapa', Dr. Swikriti Rana², Dr. Niroj Bhattarai \\ ${ }^{1}$ Assistant professor, ${ }^{2,3}$ Medical Officer \\ Department of Orthodontics and Dentofacial Orthopaedics, Kathmandu Medical College and Teaching Hospital \\ Corresponding author: Dr. Vivek Bikram Thapa; Email: vivek_thapa@yahoo.com
}

\section{ABSTRACT}

Introduction: Pulp stones are foci of calcification in the dental pulp. During the orthodontic tooth movement, a complex series of tissue reaction occurs. Studies show that the orthodontic force application may cause pulpal changes like pulpal calcifications. Hence; we assessed the prevalence of prevalence of dental pulp stones in patients undergoing orthodontic treatment.

Materials and Method: A total of 50 patients who were scheduled to undergo non-extraction orthodontic treatment were included. Pre-treatment and Post-treatment radiographs were taken in all the patients. Evaluation of the permanent molars (maxillary and mandibular) was done, both pre-treatment and post-treatment. Interpretation of the radiographs was done by skilled and experienced oral radiologists. Diagnosis of pulp stones was done when definite radiopaque bodies as dental pulp stones were noted as present or absent. All the results were recorded in Microsoft excel sheet.

Results: At pre-treatment time, prevalence of pulp stones was found to be 26 percent, while at post-treatment time, the overall prevalence of pulp stones was found to be 48 percent. Significant results were obtained while comparing the pretreatment and post-treatment prevalence of pulp stones.

Conclusion: Formation of pulp stones might be triggered under the effect of orthodontic treatment.

KEYWORDS: Orthodontic treatment, Pulp stones

\section{INTRODUCTION}

Pulp stones are foci of calcification in the dental pulp. Their cause is unknown, and no firm evidence exists that they are associated with any systemic or pulpal disturbance. ${ }^{1}$ Pulp stones are radiologically variable; they may occur as a single dense mass or as several small radiopacities seen within pulp chambers or root canals, or may extend from the pulp chamber into root canals. They occur in all tooth types but occur most commonly in molars. Pulp calcifications occurring throughout the dentition are uncommon and are usually associated with systemic or genetic disorders of dentine. ${ }^{2,3}$

During the orthodontic tooth movement, a complex series of tissue reaction occurs. The response of dental tissues to orthodontic forces are tried to be highlighted by the continuing orthodontic studies. Orthodontic tooth movement affects alveolar bone and other supporting structures, and also affects dental pulp in a way similar to surgical or chemical stimulation. Studies show that the orthodontic force application may cause pulpal changes like alteration in pulpal respiration rate, pulpal obliteration by secondary dentin formation, internal root resorption, cyst formation, pulpal necrosis and also pulpal calcifications. ${ }^{4-6}$

Hence; under the light of above mentioned data, we planned the present study to assess the prevalence of prevalence of dental pulp stones in patients undergoing orthodontic treatment.

\section{MATERIALS \& METHODS}

The present study was commenced in the department of orthodontics of dental institute of Kathmandu Medical College, Duwakot. it included assessment of 
prevalence of dental pulp stones in patients undergoing orthodontic treatment. A total of 50 patients who were scheduled to undergo non-extraction orthodontic treatment were included in the present study. Inclusion criteria for the present study included:

- Patients with negative history of any other systemic illness,

- Patients with negative history of any known drug allergy,

- Patients with absence of any form of bone metabolic disorder

- Patients withnegative history of diabetes or hypertension

Pre-treatment and Post-treatment radiographs were taken in all the patients. For the present study, ethical approval was obtained from the ethical committee of the institution(Ref:0907202004). Also written consent was obtained from all the patients after explaining in detail the entire research protocol. present study was commenced from $1^{\text {st }}$ March to $28^{\text {th }}$ August. Immediately after the end of orthodontic treatment, post-treatment radiographs were taken. Evaluation of the permanent molars (maxillary and mandibular) was done, both pre-treatment and post-treatment. Interpretation of the radiographs was done by skilled and experienced oral radiologists. Diagnosis of pulp stones was done when definite radiopaque bodies as dental pulp stones were noted as present or absent. All the results were recorded in Microsoft excel sheet and were analysed by SPSS software.

\section{RESULTS}

In the present study, a total of 50 subjects scheduled to undergo orthodontic treatment were analysed. Mean age of the patients of the present study were 13.8 years. There were 20 males and 30 females in the present study. Table 1 and Graph 1 show the comparison of overall prevalence of pulp stones at pre-treatment and post-treatment time. Overall, at pretreatment time, prevalence of pulp stones was found to be 26 percent, while at post-treatment time, the overall prevalence of pulp stones was found to be 48 percent. Significant results were obtained while comparing the pre-treatment and post-treatment prevalence of pulp stones.Table 2 and Graph 2 show the patients based comparison of dental pulp stone formation among subjects divided on the basis of gender. However; while comparing the prevalence of pulp stones in between males and females at both pre-treatment and posttreatment time, non-significant results were obtained.
Table 1: Comparison of overall prevalence of pulp stones at pre-treatment and post-treatment time

\begin{tabular}{|l|l|l|l|}
\hline $\begin{array}{l}\text { Pulp stones } \\
\text { present }\end{array}$ & $\begin{array}{l}\text { Number of } \\
\text { patients }\end{array}$ & Percentage & p- value \\
\hline Pre-treatment & 13 & 26 & \multirow{2}{*}{$0.02^{*}$} \\
\hline Post-treatment & 24 & 48 & \\
\hline *: Significant & \multicolumn{2}{|l}{} \\
\hline
\end{tabular}

Graph 1: Overall prevalence of pulp stones at pre-treatment and post-treatment time

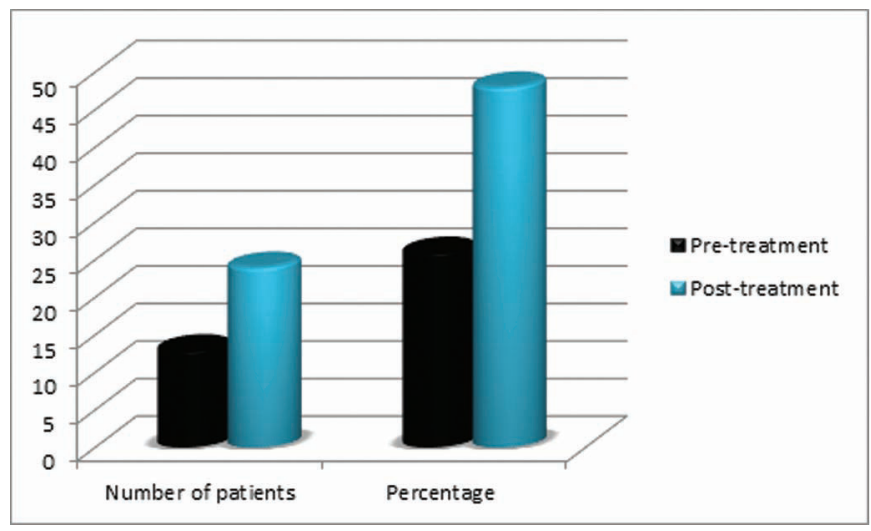

Table 2: Patients based comparison of dental pulp stone formation among subjects divided on the basis of gender

\begin{tabular}{|c|c|c|c|c|c|c|}
\hline \multirow{2}{*}{$\begin{array}{l}\text { Pulp } \\
\text { stones }\end{array}$} & \multicolumn{2}{|c|}{ Pre-treatment } & \multirow{2}{*}{$\begin{array}{l}\mathrm{P} \text { - } \\
\text { value }\end{array}$} & \multicolumn{2}{|c|}{ Post-treatment } & \multirow{2}{*}{$\begin{array}{l}\mathrm{P} \text { - } \\
\text { value }\end{array}$} \\
\hline & Males & Females & & Males & Females & \\
\hline Present & 5 & 8 & \multirow[t]{3}{*}{0.55} & 9 & 15 & \multirow[t]{3}{*}{0.48} \\
\hline Absent & 15 & 22 & & 11 & 15 & \\
\hline Total & 20 & 30 & & 20 & 30 & \\
\hline
\end{tabular}

Graph 2: Patients based comparison of dental pulp stone formation among subjects divided on the basis of gender

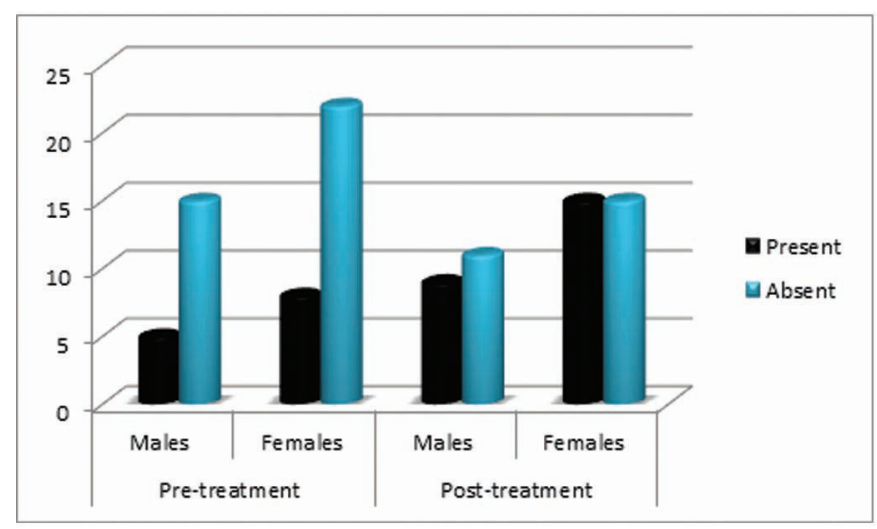




\section{DISCUSSION}

Calcification can occur in the dental pulp as discrete calcified stones or as diffuse form that can occur freely in the pulp tissue or is attached to or embedded into dentin. Depending on their microscopic structures, pulp stones have been classified into true or false form. They are not clinically apparent but are common radiographic findings. ${ }^{5-7}$

Pulp stones have variable radiographic appearance; they may be radiopaque structure within the pulp chamber or in the root. They do not have uniform shape or number. They may be round or oval, and some pulp stones inhabit most of the pulp chamber. Some may be large as 2 or $3 \mathrm{~mm}$ in diameter. Only these large calcified concretions are radiographically discernible. Pulp stones occur most commonly in molars, although they occur in all tooth types. ${ }^{7-9}$

In the present study, a total of 50 subjects scheduled to undergo orthodontic treatment were analysed. Mean age of the patients of the present study were 13.8 years. There were 20 males and 30 females in the present study. The frequency of occurrence of pulp stones has been reported to increase with age. Some studies did not find any difference in occurrence between genders, whereas other studies have found females to have more pulp stones than males. The prevalence of PS varies from $8-90 \%$, depending on the study type, design, and radiographic technique employed. Histological method of evaluation is reported to yield higher values than radiographic method. ${ }^{10}$

Overall, at pre-treatment time, prevalence of pulp stones was found to be 26 percent, while at posttreatment time, the overall prevalence of pulp stones was found to be 48 percent. Significant results were obtained while comparing the pre-treatment and posttreatment prevalence of pulp stones. Our results were in concordance with the results obtained by Ertas ET et al, who also reported similar findings. ${ }^{10}$ In their study, Ertas ET et al assessed the incidence of dental pulp stone formation during orthodontic treatment. A sample of 545 patients (334 girls and 211 boys, age range; 12-22 years) who had undergone nonextraction orthodontic treatment were included in this study. 8442 teeth ( $\mathrm{T} 1$ ) and 8410 teeth (T2), including the first and second maxillary and mandibular premolars and molars were evaluated from the pre- (T1) and posttreatment (T2) panoramic radiographs of the patients. Dental pulp stones were detected in $3 \%$ of the teeth at pretreatment panoramic radiographs and $5.2 \%$ of the teeth at posttreatment panoramic radiographs. Pulp stone prevalence increased pointedly $(2.2 \%)$ in the preand post-treatment radiographs $(P<0.001)$. Also, there was a significant difference between the age groups ( $P$ $<0.001$ ). In the maxilla, dental pulp stones were found significantly more than that in the mandible at $\mathrm{T} 1$ and $\mathrm{T} 2$ panoramic radiographs. Maxillary first molars exhibited dental pulp stones the most frequently, followed by the maxillary second molars and mandibular first molars. Orthodontic treatment may trigger the formation of dental pulp stones. ${ }^{10}$

In the present study, while comparing the prevalence of pulp stones in between males and females at both pre-treatment and post-treatment time, nonsignificant results were obtained. In another previous study conducted by Jena $D$ et al, authors assessed the prevalence of pulp stones in known South Indian orthodontic patients. A total of 3200 teeth of 200 patients were studied for the presence of pulp stones. In all, $11.5 \%$ of cases reported pulp stones before the commencement of the orthodontic treatment and $15.5 \%$ cases after completion of orthodontic treatment. Overall, $4 \%$ increase in cases were found which was statistically significant $(p<0.05) ; 5.1 \%$ of total number of teeth were evaluated in both arches before orthodontic treatment and $6.3 \%$ of teeth after orthodontic treatment revealed the presence of pulp stones. Maxillary first molar was found to be teeth with maximum number of pulp stones before and after orthodontic treatment. Their study reported the prevalence of pulp stones to be increased by $4 \%$ in the pre- and post-treatment radiographs, which was statistically significant. ${ }^{11}$

\section{CONCLUSION}

Under the light of above obtained data, the authors conclude that formation of pulp stones might be triggered under the effect of orthodontic treatment. However; we recommend further studies for better exploration of results. 


\section{REFERENCES}

1. Kansu O, Ozbek M, Avcu N, Aslan U, Kansu H, Gençtoy G. Can dental pulp calcification serve as a diagnostic marker for carotid artery calcification in patients with renal diseases? Dentomaxillofac Radiol 2009;38:542-5.

2. White SC, Pharoah MJ. Oral Radiology Principles and Interpretation. 4th ed. St Louis: Mosby; 2000.

3. Parekh S, Kyriazidou A, Bloch-Zupan A, Roberts G. Multiple pulp stones and shortened roots of unknown etiology. Oral Surg Oral Med Oral Pathol Oral Radiol Endod. 2006;101:139-142.

4. Haselden K, Hobkırk JA, Goodman JR, Jones SP, Hemmings KW. Root resorption in retained deciduos canine and molar teeth without permanent successors in patients with severe hypodontia. Int J Paediatr Dent. 2001;11:171-178.

5. Malmgren O, Levander E. Minimizing orthodontically induced root resorption. In: Graber TM, Eliades T, Athanasiou AE, editors. Risk management in orthodontics: experts' guide to malpractice. Quintessence Publishing Co., Inc; Chicago: 2004. P.3333p. 61-73

6. Moss-Salentijn L, Klyvert MH. Epithelially induced denticles in the pulps of recently erupted, noncarious human premolars. $\mathrm{J}$ Endod 1983;9:554-60.

7. Rozsa N, Nagy K, Vajo Z, Gabris K, Soos A, Alberth M, Tarjan I. Prevalence and distribution of permanent canine agenesis in dental paediatric and orthodontic patients in Hungary. Eur J Orthod. 2009;31:374-379.

8. Hillmann G, Geurtsen W. Light-microscopical investigation of the distribution of extracellular matrix molecules and calcifications in human dental pulps of various ages. Cell Tissue Res 1997;289:145-54.

9. Edds AC, Walden JE, Scheetz JP, Goldsmith LJ, Drisko CL, Eleazer PD. Pilot study of correlation of pulp stones with cardiovascular disease. J Endod 2005;31:504-6.

10. Ertas ET1, Veli 12, Akin M3, Ertas H4, Atici MY1. Dental pulp stone formation during orthodontic treatment: A retrospective clinical follow-up study. Niger J Clin Pract. 2017 Jan;20(1):37-42. doi: 10.4103/1119-3077.164357.

11. Jena D1, Balakrishna K2, Singh S3, Naqvi ZA4, Lanje A5, Arora N6. A Retrospective Analysis of Pulp Stones in Patients following Orthodontic Treatment. J Contemp Dent Pract. 2018 Sep 1;19(9):1095-1099. 